\title{
Hydrocarbon patterns in Cleisostoma scolopendrifolium (Orchidaceae) as a key mechanism for pollination
}

\author{
Hyun-Deok SON, Seon A YUN', Seung-Chul KIM² and Hyoung-Tak IM ${ }^{3 *}$ \\ Ministry of Environment, Sejong 30103, Korea \\ ${ }^{I}$ Department of Environmental and Forest Biology, State University of New York, Syracuse, NY 13210, USA \\ ${ }^{2}$ Department of Biological Sciences, Sungkyunkwan University, Suwon 16419, Korea \\ ${ }^{3}$ Department of Biological Sciences, Chonnam National University, Gwangju 61186, Korea
}

(Received 6 May 2020; Revised 8 June 2020; Accepted 24 June 2020)

\begin{abstract}
Cleisostoma scolopendrifolium is an orchid species solely pollinated by the male bee Megachile yasumatsui. Although C. scolopendrifolium is an endangered species in Korea, little is known about its pollination mechanisms or the profiles of its chemical attractants. This study provides evidence that the Cleisostoma orchid attracts male bees as pollinators by mimicking female mating signals. We found 13 hydrocarbons in the Cleisostoma orchid flower presumed to be involved in sex pheromone mimicry: five alkanes (tricosane, pentacosane, heptacosane, nonacosane, and hentriacontane), compounds of cuticular hydrocarbons which function as chemical cues for the recognition of mates and species in social insects; and eight alkenes ((z)-9-tricosene, (z)-9-pentacosene, (z)-11-pentacosene, (z)-9-heptacosene, (z)-11-heptacosene, (z)-9-nonacosene, (z)-11-nonacosene, and (z)-11-hentriacontene) which serve as sex pheromones in several insects. We suggest that these hydrocarbons play a key role in the pollination mechanism between Cleisostoma orchids and Megachile bees.
\end{abstract}

Keywords: pollination, Megachile, Cleisostoma, hydrocarbon, sex pheromone

Zoophilic plants attract pollen vectors with floral signals that are associated with rewards or release innate responses in the pollinators (Vogel, 1983). These plants imitate signals attractive to pollinators, a phenomenon called floral mimicry. Generalized mimicry is assumed to be common among food deceptive plants (Dafini, 1984). Batesian mimicry has been demonstrated only rarely among food deceptive species, but is well established in sexually deceptive orchids. Sexual deception differs from food deception by exclusive attraction of male insect pollinators that have the motivation of mating rather than searching food. Accordingly, pollination is often species specific and floral odor, a mimicry of the pollinators sex pheromone, is crucial for pollinator attraction (Paulus and Gack, 1990).

In the European Ophrys sphegodes active chemicals are simple, more or less ubiquitous constituents of plant cuticular hydrocarbons that release behavioral activity only on specific relative amounts (Schiestl et al., 2000). A primary function of these compounds, that are a part of the wax layer on the cuticle, is to prevent dehydration, and pollinator attraction seems to have evolved secondarily through a shift in function (Schiestl et al., 1999). Australian Chiloglottis trapeziformis attracts its pollinator with a single compound, Chiloglottone (Schiestl et al., 2003) which tricks the male thynnine wasp (Neozeleboria cryptoides). As the result of analysis of $C$. trapeziformis scent revealed the orchid was producing chiloglottone, which is also a pheromone made by female wasps.

Cleisostoma scolopendrifolium (Fig. 1A-D), one of endangered orchid species in Korea, is categorized as EN B2b (iii, iv, v), c (iii, iv, v) in the Korean Red List of Threatened Species and is currently protected under the Endangered Wild Life Protection Law (National Institute of Biological Resources, 2014). Despite its conservation status, we know very little about pollinators, pollination mechanisms, and role of pollinators in seed production.

Megachile yasumatsui male bee is the only one pollinator

\footnotetext{
*Author for correspondence: ihtplant@hanmail.net
} 

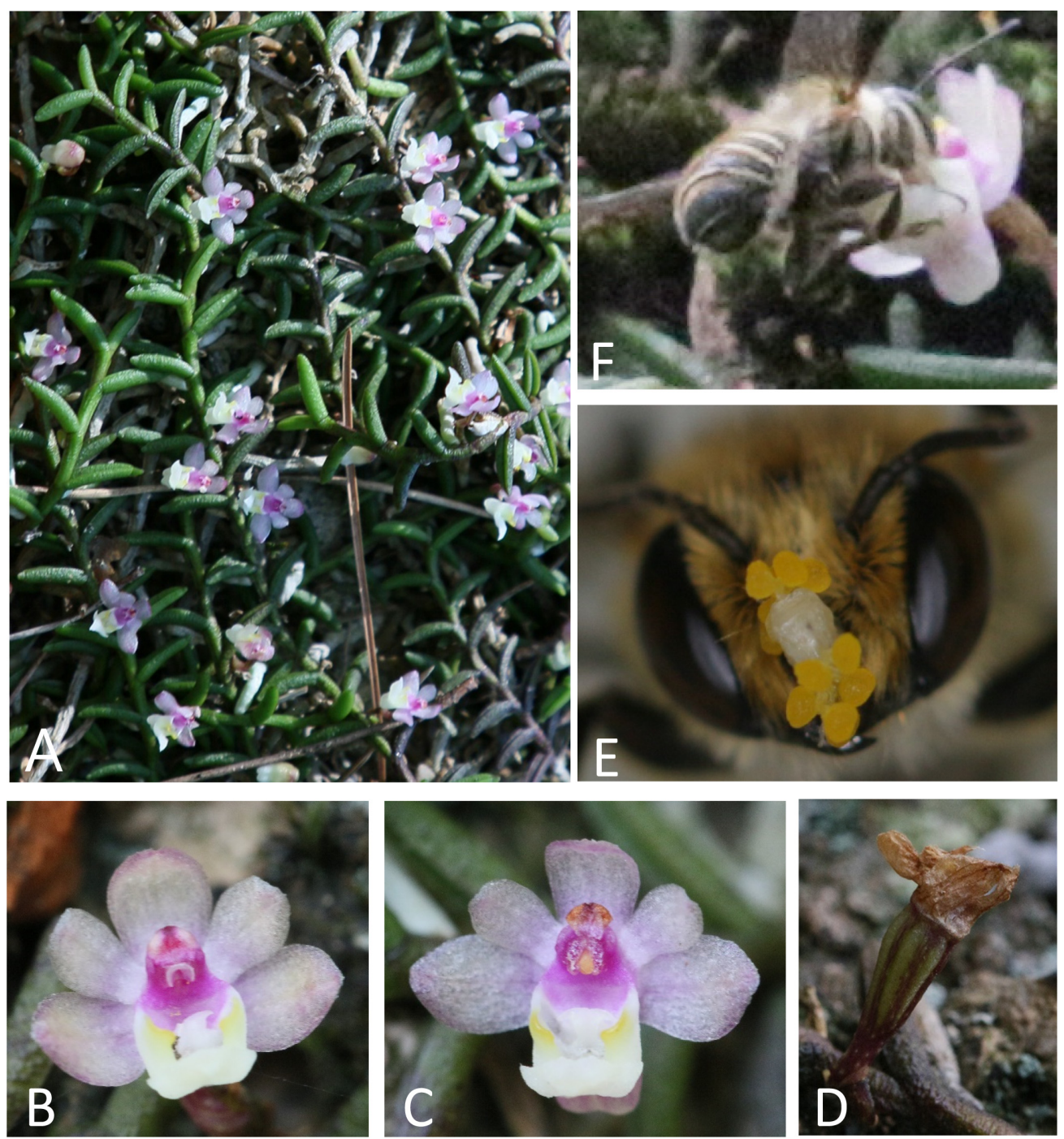

Fig. 1. Cleisostoma scolopendrifolium and its pollinator, Megachlile yasumatsui. A. Population of C. scolopendrifolium in Mokpo. B. Before pollination, pollinia are covered by anther cap. C. After pollination, pollinia are transferred to the stigma. D. Fruit. E. Pollinia attached to the head of M. yasumatsui (front view). F. M. yasumatsui visiting a flower.

species of C. scolopendrifolim orchid and the bee visits only when the flowers produce odor. It became evident that male Megachile bees transferred the pollinia attached to the heads which had visited the orchids (Son et al., 2017).

Sexual mimicry, pollination system functions primarily through the species-specific imitation of female sex pheromones. This mechanism of chemical mimicry showed that specific patterns of $n$-alkenes (unsaturated hydrocarbon) play a key role in Ophrys orchid for attraction of male pollinators to the flowers (Schiestl et al., 2000). Alkanes, saturated analogues of $n$-alkenes, were showed to have synergistic effect by increasing the intensity of male responses.

This chemical mimicry is the presumed mechanism behind the attraction of only male Megachile bees. Subsequently, the objective of this research is to analyze the hydrocarbon patterns of $C$. scolopendrifolium flowers, and to reveal the presence of specific substances which only attract male Megachile bees.

\section{Materials and Methods}

\section{Sample collection}

Cleisostoma scolopendrifolium plants were collected at Yudalsan Mt. of Mokpo in the southern part of Korea. For all scent (hexane extracts) collection, fresh, unpollinated flowers were used. Flowers and leaves were extracted by the same dilution factor. One milliliter $(\mathrm{mL})$ of hexane were extracted from $0.1 \mathrm{~g}$ of each sample (Uvasol, Merck. Darmstadt, Germany) by shaking in a $2 \mathrm{~mL}$ vial for $1 \mathrm{~min}$. The flowers 
and leaves were then removed, and the samples were stored at $-20^{\circ} \mathrm{C}$ until the analysis.

\section{Extraction procedure}

Before the gas chromatographic analysis, $100 \mathrm{ng}$ of octadecane (purity 99.8\%, Fluka, Buchs, Switzerland) were added to all samples as an internal standard. For identification of compounds, $1 \mu \mathrm{L}$ of each sample was injected on column into a Trace GC Ultra with a DSQ mass spectrometer (MS; Thermo electron Corp., Milano, Italy), and equipped with HP5 columns (5\% phenyl-methyl-polysiloxane, $30 \mathrm{~m} \times 0.32 \mathrm{~mm} \times$ $0.25 \mu \mathrm{m}$ film thickness, Agilent Technologies). Helium served as the carrier gas $(2 \mathrm{~mL} / \mathrm{min}$, constant flow mode). The oven was kept at $45^{\circ} \mathrm{C}$ for $1 \mathrm{~min}$ and then heated to $280^{\circ} \mathrm{C}$ at a rate of $10^{\circ} \mathrm{C} / \mathrm{min}$. The transfer line to the MS was heated to $220^{\circ} \mathrm{C}$. The ion-source of the MS was heated to $250^{\circ} \mathrm{C}$, and starting after 5 minutes it was run in full scan mode; 1.31 scans/s were done at a scan rate of $500.3 \mathrm{amu} / \mathrm{s}$, and the mass range was 50-420. Compounds were identified by comparison of mass spectra and retention times with those of synthetic reference compounds. On a HP-5 column, alkenes eluted before the corresponding alkanes. Rather than identifying all compounds present in the extracts, we focused on straight chain saturated hydrocarbons (n-alkanes) and unsaturated ( $n$-alkenes) hydrocarbons with double bond position $5,7,9$, or 11, and of chain lengths 21-29.

\section{Results}

\section{Occurrence of alkanes and alkenes}

$n$-alkanes (saturated hydrocarbons) of chain lengths 21-32 were present in leaf and flower extract, but varying absolute abundance (Fig. 2). Odd chain-lengths alkanes with 23 carbon atoms or more were especially abundant in flower extract, i.e., tricosane, pentacosane, heptacosane, nonacosane, and hentriacontane (Fig. 3, Table 1). These five alkanes are also found in the cuticular layer of several insects. Tricosane is a cuticular hydrocarbon (CHC) that is associated with mate recognition in Drosophila suzukii (Snellings et al., 2018). Pentacosane is released in the form of pheromones produced by honey bees during their waggle dancing behavior (Thom et al., 2007). Heptacosane is a CHC found in the weaver ant, Oecophylla smaragdina (Bloomquist and Bagneres, 2010). Nonacosane is a pheromone released by Orgyia leucostigma (Grant et al., 1987), and functions as a chemical signal transmitter among female Anopheles stephensi mosquitos (Brei et al., 2000). Finally, hentriacontane, a substance composing cuticular lipids in the male cricket, Gryllus bimaculatus, induces sex specific behavior (Iwasaki and Katagiri, 2008).

No alkenes were detected in the leaf extract, whereas (z)-9tricosene, (z)-11-pentacosene, (z)-12-pentacosene, (z)-9heptacosene, (z)-11-heptacosene, (z)-9-nonacosene, (z)-11nonacosene, and (z)-11-hentriacontene were found in the flower extract (Fig. 3, Table 1). (z)-9-tricosene is a sex pheromone produced by the female housefly Musca domestica (Carlson et al., 1971). (z)-9-pentacosene is a contact sex pheromone in the locust borer Megacyllene robiniae (Ginzel et al., 2003). (z)-11-pentacosene is a sex pheromone component in Drosophila virilis (Oguma et al., 1992). (z)-9-heptacosene is a mating stimulating pheromone of the horn fly Haematobia irritans (Bolton et al., 1980). (z)-11-heptacosene is a sex pheromone in the alfalfa leaf-cutter bee Megachile rotundata

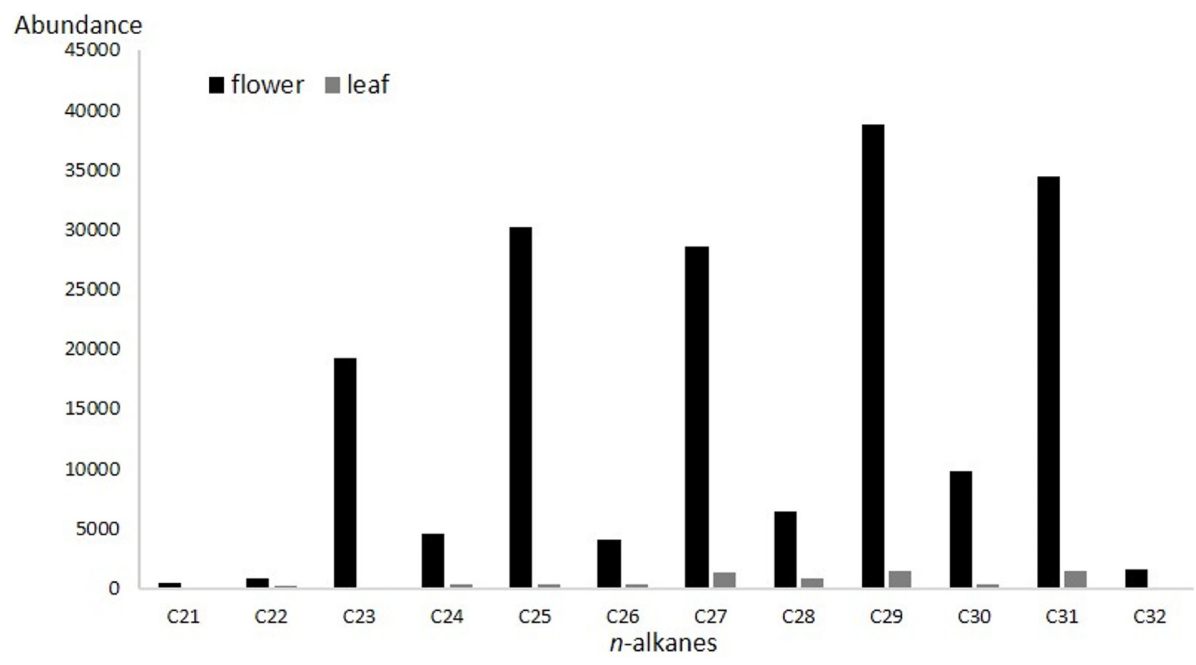

Fig. 2. Mean relative amounts of saturated hydrocarbons in Cleisostoma scolopendrifolium flower and leaf extract. 


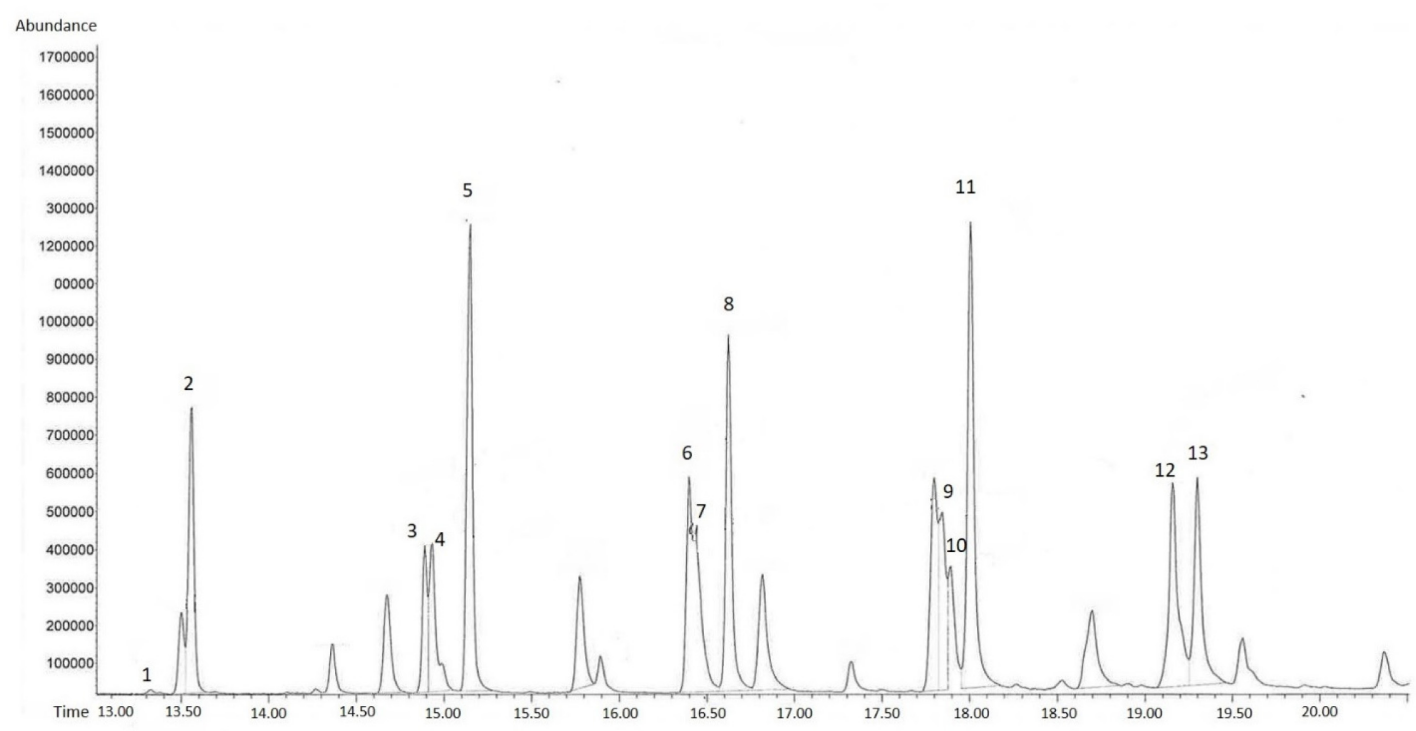

Fig. 3. Gas chromatographic analysis of Cleisostoma scolopendrifolium flower extract. Numbered peaks correspond to compounds. The names of compounds are indicated in Table 1.

Table 1. Occurrence of straight chain saturated hydrocarbons ( $n$-alkanes) and unsaturated ( $n$-alkenes) hydrocarbons of flower extract of Cleisostoma scolopendrifolium indexed by the insects which produce them.

\begin{tabular}{ccl}
\hline \hline No. & Compound & \multicolumn{1}{c}{ Properties } \\
\hline 1 & (z)-9-Tricosene & Sex pheromone produced by female housefly (Carlson et al., 1971) \\
2 & Tricosane & CHCs of Drosophila suzukii (Snellings et al., 2018) \\
3 & (z)-11-Pentacosene & Sex pheromone component in Drosophila virilis (Oguma et al., 1992) \\
4 & (z)-9-Pentacosene & Contact sex pheromone of the locust borer (Ginzel et al., 2003) \\
5 & Pentacosane & CHCs of honey bee (Thom et al., 2007) \\
6 & (z)-11-Heptacosene & Sexual pheromone in the alfalfa leaf-cutter bee Megachile rotundata \\
& (Paulmier et al., 1999) \\
7 & (z)-9-Heptacosene & Mating stimulant pheromone of the horn fly (Bolton et al., 1980) \\
8 & Heptacosane & CHCs of weaver ant (Bloomquist and Bagneres, 2010) \\
9 & (z)-11-Nonacosene & Sex pheromone of Sirex noctilio elicited copulatory responses from males (Böröczky et al., 2009) \\
10 & (z)-9-Nonacosene & Major component of the contact sex pheromone of beetle Megacyllene caryae (Ginzel et al., 2006) \\
11 & Nonacosane & Sex pheromone of Orgyia leucostigma (Grant et al., 1987) \\
12 & (z)-11-Hentriacontene & Mating stimulant pheromone of Fannia femoralis (Uebel et al., 1978) \\
13 & Hentriacontane & CHCs of male cricket (Iwasaki and Katagiri, 2008) \\
\hline CHC, cula
\end{tabular}

CHC, cuticular hydrocarbons.

(Paulmier et al., 1999). (z)-9-nonacosene is major component of the contact sex pheromone of beetle Megacyllene caryae (Ginzel et al., 2006). (z)-11-nonacosene is sex pheromones in Sirex noctilio that elicited copulatory responses from males (Böröczky et al., 2009). Lastly, (z)-11-hentriacontene is a mating stimulating pheromone in Fannia femoralis (Uebel et al., 1978).

\section{Discussion}

In early 1900s, Coleman (1927) discovered independently that some orchids, without producing nectar, mimic mating signals of insects and are pollinated by males attempting copulation on the flowers. It took some years to establish the concept of chemical mimicry between the European Ophrys 
sphegodes orchid and a male Andrena nigroaenea pollinator (Schiestl et al., 1999). In the preliminary research, it was believed that the male bees attempted copulation with an orchid flower due to physical mimicry of the female bees' appearance. However, further investigation of orchid floral scents elucidated that semiochemicals which elicit copulation behavior are located on both the surface of the females' cuticle and the surface of the flowers. Most of the alkanes and alkenes occurred in similar patterns in both the bees and orchids (Schiestl et al., 2000).

As for C. scolopendrifolium, odd chain- lengths $n$ - alkanes in the leaf and flower were present in similar patterns, but there were especially abundant in the flower than in the leaf. While no alkenes were found in leaf extract, eights were found exclusively in flower extract. In the case of $C$. scolopendrifolium, male M. yasumatsui are the sole pollinator. This is in large part because hydrocarbon patterns in Cleisostoma orchid proposed possibilities, the orchid flowers produce semiochemicals similar to that of Megachile females' sex pheromones and adopts chemical mimicry as a pollination mechanism to utilize male Megachile bees as its pollinator.

Future research should focus on two additional goals - to identify hydrocarbon patterns in female Megachilie bee, and to verify whether male Megachile bees respond to dummy flowers coated with compounds from actual $C$. scolopendrifolium flowers. This further evidence would add to the robustness of the current findings.

ORCID: Hyun-Deok SON https://orcid.org/0000-0002-35041908; Seon A YUN https://orcid.org/0000-0002-4961-7189; Seung-Chul KIM https://orcid.org/0000-0003-0559-6782; Hyoung-Tak IM https://orcid.org/0000-0002-6333-6244.

\section{Acknowledgments}

We sincerely thank Prof. Dr. Florian P. Schiestl and Dr. Huber (University of Zurich, Switzerland) for their assistance with the GC assay analysis. Specially, Dr. Schiestl is gratefully acknowledged for support and much helpful advice. Lastly, we thank the Korean Ministry of Environment for allowing us to access and examine these endangered orchid plants. This research was supported by the Basic Science Research Program through the National Research Foundation of Korea (NRF), and funded by the Ministry of Science and ICT (NRF 2017R1D1A2B03028800).

\section{Conflict of Interest}

The authors declare that there are no conflicts of interest.

\section{Literature Cited}

Blomquist, G. J. and A.-G. Bagneres. 2010. Introduction: history and overview of insect hydrocarbons. In Insect Hydrocarbons. Blomquist, G. J. and A.-G. Bagneres (eds.), Cambridge University Press, London. Pp. 3-18.

Bolton, H. T., J. F. Butler and D. A. Carlson. 1980. A mating stimulant pheromone of the horn fly, Haematobia irritans (L.): demonstration of biological activity in separated cuticular components. Journal of Chemical Ecology 6: 951-964.

Böröczky, K., D. J. Crook, T. H. Jones, J. C. Kenny, K. E. Zylstra, V. C. Mastro and J. H. Tumlinson. 2009. Monoalkenes as contact sex pheromone components of the woodwasp Sirex noctilio. Journal of Chemical Ecology 35: 1202-1211

Brei, B., J. D. Edman, B. Gerade and J. M. Clark. 2000. Relative abundance of two cuticular hydrocarbons indicates whether a mosquito is old enough to transmit malaria parasites. Journal of Medical Entomology 41: 807-809.

Carlson, D. A., M. S. Mayer, D. L. Sillhacek, J. D. James, M. Beroza and B. A. Bierl. 1971. Sex attractant pheromone of the housefly: isolation, identification and synthesis. Science 174 : 76-78.

Coleman, E. 1927. Pollination of the orchid Cryptostylis leptochila. Victorian Naturalist 44: 20-22.

Dafni, A. 1984. Mimicry and deception in pollination. Annual Review of Ecology and Systematics 15: 259-278

Ginzel, M. D., J. G. Millar and L. M. Hanks. 2003. (Z)-9-Pentacosene contact sex pheromone of the locust borer, Megacyllene robiniae. Chemoecology 13: 135-141.

Ginzel, M. D., J. A. Moreira, A. M. Ray, J. G. Millar and L. M. Hanks. 2006. (Z)-9- Nonacosene-major component of the contact sex pheromone of the beetle Megacyllene caryae. Journal of Chemical Ecology 32: 435-451.

Grant, G. G., D. Frech, L. MacDonald, K. N. Slessor and G. G. S. King. 1987. Copulation releaser pheromone in body scales of female whitemarked tussock moth, Orgyia leucostigma (Lepidoptera: Lymantriidae): identification and behavioral role. Journal of Chemical Ecology 13: 345-356.

Iwasaki, M. and C. Katagiri. 2008. Cuticular lipid and odors induce sex specific behaviors in the male cricket Gryllus bimaculatus. Comparative Biochemistry and Physiology, Part A: Molecular \& Integrative Physiology 149: 306-313.

National Institute of Biological Resources. 2014. Korean Red List of Threatened Species. 2nd ed. Jisungsa Publishing Co., Incheon, $242 \mathrm{pp}$.

Oguma, Y., T. Nemoto and Y. Kuwajara. 1992. (Z)-11-Pentacosene is the major sex pheromone component in Drosophila virilis (Diptera). Chemoecology 3: 60-64. 
Paulmier, I., A.-G, Bagnères, C. M. M. Alfonso, G. Dusticier, G. Rivière and J.-L. Clément. 1999. Alkenes as a sexual pheromone in the alfalfa leaf-cutter bee Megachile rotundata. Journal of Chemical Ecology 25: 471-490.

Paulus, H. F. and C. Gack. 1990. Pollinators as prepollinating isolation factors: evolution and speciation in Ophrys (Orchidaceae). Israel Journal of Botany 39: 43-79.

Schiestl, F. P., M. Ayasse, H. F. Paulus, C. Löfstedt, B. S. Hansson, F. Ibarra and W. Francke. 1999. Orchid pollination by sexual swindle. Nature 399: 421-422.

Schiestl, F. P., M. Ayasse, H. F. Paulus, C. Löfstedt, B. S. Hansson, F. Ibarra and W. Francke. 2000. Sex pheromone mimicry in the early spider orchid (Ophrys sphegodes): patterns of hydrocarbons as the key mechanism for pollination by sexual deception. Journal of Comparative Physiology 186: 567-574.

Schiestl, F. P., R. Peakall, J. G. Mant, F. Ibarra, C. Schulz, S. Franke and W. Francke. 2003. The chemistry of sexual deception in an orchid-wasp pollination system. Science 302: 437438.
Snellings, Y., B. Herrera, B. Wildemann, M. Beelen, L. Zwarts, T. Wenseleers and P. Callaerts. 2018. The role of cuticular hydrocarbons in mate recognition in Drosophila suzukii. Scientific Report 8: 4996.

Son, H.-D., H.-T. Im and S.-W. Choi. 2017. Study on the pollinator and pollination mechanism of an endangered orchid species, Sarcanthus scolopendrifolius Makino (Orchidaceae) in Korea. Journal of Apiculture 32: 199-203.

Thom, C., D. C. Gilley, J. Hooper and H. E. Esch. 2007. The scent of waggle dance. PLoS Biology 5: e228.

Uebel, E. C., M. Schwarz, R. W. Miller and R. E. Menzer. 1978. Mating stimulant pheromone and cuticular lipid constituents of Fannia femoralis (Stein) (Diptera: Muscidae). Journal of Chemical Ecology 4: 83-93.

Vogel, S. 1983. Ecophysiology of zoophilic pollination. In Encyclopedia of Plant Physiology, Physiological Plant Ecology New Series, Vol. 12c. Lange, O. L., P. S. Nobel, C. B. Osmond and H. Zeigler (eds.), Springer, Berlin. Pp. 560-611. 